\title{
O poder colonial em ação: contribuições de Max Gluckman e Georges Balandier para o estudo do colonialismo
}

\author{
Gabriel Calil Maia Tardelli ${ }^{1}$
}

Universidade de Brasília

Resumo: Neste ensaio, analiso as contribuições de Max Gluckman e Georges Balandier para o estudo do colonialismo, a exemplo dos conceitos de situação social e situação colonial, bem como das noções de conflito e mudança social. Na parte final, relaciono as situações etnográficas e as teorias elaboradas por eles com a noção foucaultiana de poder e com o conceito de poder tutelar, de modo a esboçar uma compreensão inicial a respeito de como o colonialismo é atualizado contemporaneamente no Brasil.

Palavras-chave: colonialismo; conflito; Max Gluckman; Georges Balandier. 


\title{
The colonial power in action: contributions of Max Gluckman and Georges Balandier to the study of colonialism
}

\begin{abstract}
In this essay, I analyze the contributions of Max Gluckman and Georges Balandier to the study of colonialism, such as the concepts of social situation and colonial situation, as well as the notions of conflict and social change. In the end, I relate the ethnographic situations and theories elaborated by them with the Foucauldian notion of power and with the tutelary power concept, in order to sketch an initial understanding of how colonialism is updated contemporaneously in Brasil.
\end{abstract}

Keywords: colonialism; conflict; Max Gluckman; Georges Balandier.

\section{El poder colonial en acción: contribuciones de Max Gluckman y Georges Balandier para el estudio del colonialismo}

\begin{abstract}
Resumen: En este ensayo, analizo las contribuciones que de Max Gluckman y Georges Balandier para el estudio del colonialismo, a ejemplo de los conceptos de situación social y situación colonial, así como de las nociones de conflicto y cambio social. En la parte final, relaciono las situaciones etnográficas y las teorías elaboradas por ellos con la noción foucaultiana de poder y con el concepto de poder tutelar, de modo a esbozar una comprensión inicial acerca de cómo el colonialismo es actualizado contemporáneamente en Brasil.
\end{abstract}

Palabras clave: colonialismo; conflicto; Max Gluckman; Georges Balandier. 


\section{O encontro colonial}

A despeito da existência de inúmeras histórias da antropologia, são inegáveis as relações entre a disciplina em seus passos iniciais e o colonialismo (KANT DE LIMA, 2008; ERIKSEN e NIELSEN, 2010). Ainda que possamos questionar até que ponto os antropólogos e as antropólogas daquele período compactuaram ou não com o sistema colonial (KUPER, 1978), o fato é que as relações de poder coloniais forjaram as condições de possibilidade para que o conhecimento antropológico pudesse ser produzido (NADER, 1972; ASAD, 2017).

Nas décadas de 1920 e 1930, houve uma expansão da antropologia inglesa do Pacífico até a África (ERIKSEN e NIELSEN, 2010). A antropologia política ${ }^{2}$ recebeu maior atenção justamente quando alguns alunos de Bronislaw Malinowski e A. R. Radcliffe-Brown começaram a trabalhar em contextos africanos. Lá, encontraram formas de governo organizadas em Estados centralizados e instituições políticas que se assemelhavam mais aos reinos, principados e repúblicas europeias do que as formas supostamente indiferenciadas e desarticuladas estudadas anteriormente pelos antropólogos (COLSON, 1979). Assim, "puestos políticos bien definidos, una jerarquía de autoridad y comunicación, así como el control explícito de la fuerza organizada, eran rasgos familiares y podían ser manejados en términos de las teorías políticas del momento (COLSON, 1979: 22).

Segundo Gentili (2000: 46), esses trabalhos foram motivados "seja pelas exigências de conhecimento da política colonial britânica de administração 'indireta', seja pela descoberta de que no continente africano continuavam a existir e a funcionar sistemas políticos 'tradicionais', quando, no resto do mundo, sistemas desse tipo estavam desaparecendo rapidamente”. Sob essa perspectiva, enquanto um projeto e, ao mesmo tempo, uma especialização da pesquisa antropológica, a antropologia política teve seu campo de estudos delimitado dentro da antropologia social ou da etnologia, através da descrição e da análise dos sistemas políticos (estruturas, processos e representações) das sociedades ditas "primitivas" ou "arcaicas" (BALANDIER, 1969).

No prefácio que escrevera para African political systems, coletânea organizada por Meyer Fortes e Edward Evans-Pritchard, publicada em 1940, RadcliffeBrown definiu o que seria o domínio do político dentro de uma sociedade tradicional: "a consideração dos fatos relativos à lei e à guerra, o estudo dos conteúdos normativos e constitucionais, bem como dos padrões de conflito e beligerância" (PACHECHO DE OLIVEIRA, 1986).

Influenciado pelo estruturalismo de Radcliffe-Brown, Evans-Pritchard demonstrou como os Nuer organizavam-se politicamente a partir de uma estrutura de linhagem, a qual dispensava a presença de um poder centralizador. Fortes, por

${ }^{2}$ Filio-me, aqui, a opinião de Pacheco de Oliveira (1986), para quem a antropologia política não consiste em uma disciplina autônoma dentro da antropologia; ao contrário, o campo da antropologia política está ligado às contribuições dadas pelos antropólogos sociais ao domínio do "político". 
sua vez, observou que os Tallensi exerciam um controle político sobre povos étnica, linguística e culturalmente diferentes, através da articulação entre uma estrutura de clãs e uma estrutura de ritual (PACHECHO DE OLIVEIRA, 1986).

Para os autores africanistas das décadas de 1930 e 1940 - notadamente aqueles orientados pelo estrutural-funcionalismo -, a política era percebida como um domínio distinto do domínio do parentesco. Esses antropólogos buscavam normas e prescrições que permeavam o funcionamento dos sistemas políticos, além de pressuporem que as sociedades estudadas se encontravam em uma "estabilidade relativa" (PACHECO DE OLIVEIRA, 1986).

Embora também pertencessem à essa "linhagem" de antropólogos, Edmund Leach e Max Gluckman romperam, em alguma medida, com o "presente etnográfico", isto é, com o predomínio da dimensão sincrônica que norteava aquelas monografias etnográficas. Com as publicações de Political systems of highland Burma, em 1954, e de Analysis of a social situation in modern Zululand, em 1958,3 Leach e Gluckman contribuíram, respectivamente, para uma aproximação da antropologia com a história e, consequentemente, para o desenvolvimento de estudos que passaram a levar em consideração as mudanças sociais.

Gluckman ingressara na antropologia em meados da década de 1930, quando a influência de Malinowski cedia lugar à de Radcliffe-Brown (KUPER, 1978). Não obstante, frequentou os seminários do antropólogo polaco e manteve com ele um diálogo constante através de suas obras - de maneira crítica ou elogiosa4 (GLUCKMAN, 1947; 1975; 2010). Nascido em Johannesburg, na África do Sul, estudara antropologia social, primeiramente, na Universidade de Witwatersrand, sob a orientação da Sra. Hoernlé, que seguia os passos de Radcliffe-Brown (KUPER, 1978).

Em 1934, foi para Oxford, e fez seu doutorado em 1936, sob a orientação de Evans-Pritchard e Fortes. Entre 1936 e 1938, realizou trabalho de campo na Zululândia, tendo publicado os resultados dessa pesquisa em 1940, em um capítulo sobre os Zulu em African political systems e a primeira parte de Analysis of a social situation in modern Zululand (KUPER, 1978). Em relação ao primeiro texto, Kuper (1978: 173) afirma que "este foi o único escrito realista de análise política, tratando do contexto de dominação racial”, que compôs aquela coletânea. Quanto ao segundo trabalho, Gluckman demonstra "como a sociedade política plural formada por dominação colonial ou colonizadora deve fornecer o quadro de referência para a compreensão dos sistemas 'tribais' locais” (KUPER, 1978: 173).

Tendo o sul da África como uma das principais bases etnográficas, os estudos provenientes do Rhodes-Livingstone Institute, localizado na África Central, contrastavam significativamente com os trabalhos dos antropólogos de Oxford e Cambridge na África Ocidental e Oriental (KUPER, 1978). Gluckman ingressou no Instituto em 1939 - um ano após a sua fundação -, sucedendo Godfrey Wilson na direção em 1941. Os antropólogos ligados a esse centro de pesquisa estudavam desde processos de urbanização, migração e crescimento populacional até a proletarização e a maneira pela qual formas tradicionais, como o parentesco, eram mantidas mesmo em situações de mudanças bruscas (ERIKSEN e NIELSEN,

\footnotetext{
3 A primeira parte de Analysis of a social situation in modern Zululand foi publicada em 1940; a monografia completa saiu em 1958.

4 "A moderna Antropologia inglesa foi durante muito tempo dominada por Bronislaw Malinowski e por A. R. RadcliffeBrown. Este último contribuiu com um enfoque teórico mais fecundo, embora os antropólogos ingleses já tenham superado em grande parte as suas conquistas. Em todo caso, considero Malinowski como o verdadeiro pai da moderna Antropologia inglesa. A teoria é apenas um dos lados da ciência: o outro lado, igualmente importante, é o tipo de dado que se submete à análise teórica" (GLUCKMAN, 1975: 63).
} 
2010). Esses pesquisadores, de acordo com Eriksen e Nielsen (2010: 107) "investigavam as relações raciais em cidades mineradoras numa época em que grande parte da antropologia predominante ainda considerava a discriminação racial como domínio da sociologia”.

Na França, o Pacífico e a África eram ambos importantes campos de pesquisa etnográfica desde os anos 1920. Fortemente influenciado pelos estudos desenvolvidos pelo Rhodes-Livingstone Institute, como os de Gluckman (COPANS, 2001), Georges Balandier, após a II Guerra Mundial, fortaleceu ainda mais as pesquisas africanistas5 (ERIKSEN e NIELSEN, 2010). Para ele, o crescente interesse despertado pelo domínio do político na década de 1960 se devia, dentre outros fatores, aos processos de descolonização da África (BALANDIER, 1969).

Balandier nasceu em uma pequena aldeia de Haute-Saone, um departamento da França. Diplomou-se pelo Instituto de Etnologia da Sorbonne. Recrutado pelo Escritório de Pesquisa Científica Colonial6, passou a trabalhar para o Instituto Francês da África Negra, em Dakar, no ano de 1946. Em África, viveu na Guiné, Gabão e Congo, lugares sobre os quais escreveu em duas importantes obras para os estudos africanistas: Sociologie actuelle de l'Afrique noire e Sociologie des Brazzavilles noires, publicadas em 1955.7

Em um artigo intitulado "La situation coloniale: approche théorique", publicado nos Cahiers internationaux de sociologie em $1951^{8}$, Balandier (2014) sustenta que os antropólogos que atuaram em África, Ásia e Oceania não poderiam/deveriam ter ignorado o contexto colonial. Por um lado, alguns pesquisadores estiveram em busca de sociedades "puras" e inalteradas, enquanto outros especulavam sobre os destinos da civilização ou sobre as origens da sociedade; por outro, mesmo os antropólogos que se engajavam em uma "antropologia aplicada" acabaram por enfatizar determinados aspectos daquele contexto em detrimento de outros.

Os problemas raciais, na opinião de Balandier (2014: 54), receberam pouca atenção desses pesquisadores, "o que se explica pela atenção concedida às culturas mais do que às sociedades, também, pela preocupação (mais ou menos consciente) de não questionar os próprios fundamentos (e a ideologia) da sociedade colonial da qual participam”.

Neste ensaio, pretendo analisar as contribuições que Gluckman e Balandier deram para o estudo do colonialismo, a exemplo dos conceitos de situação social (GLUCKMAN, 2010) e situação colonial (BALANDIER, 2014), bem como as noções de conflito e mudança social. Na parte final, relaciono as situações etnográficas e as teorias elaboradas por eles com a noção foucaultiana de poder (1995; 2018) e com o conceito de poder tutelar (SOUZA LIMA, 1995), de modo a esboçar uma compreensão inicial a respeito de como o colonialismo é atualizado contemporaneamente.

\footnotetext{
5 Um de seus alunos, o antropólogo francês Claude Meillassoux - que chegou a elaborar uma tipologia dos "modos de produção pré-capitalistas" em África - escreveu em um prefácio que Balandier o havia introduzido "à melhor antropologia do momento - isto é, a antropologia inglesa", tecendo elogios a Schapera, Gluckman, Monica Wilson e outros (ERIKSEN e NIELSEN, 2010, p. 138).

${ }^{6}$ Anteriormente, chamava-se Escritório de Pesquisa Científica e Técnica no Exterior (ORSTOM, na sigla em francês). Hoje, chamam-no de Instituto de Pesquisa para o Desenvolvimento (IRD, na sigla em francês).

7 Disponível em: https://www.lemonde.fr/disparitions/article/2016/10/o5/la-mort-de-georges-balandier-sociologuespecialiste-de-l-afrique_5008603_3382.html. Acesso em: 20 dez. 2018.

8 Embora este artigo não tenha sido republicado, as ideias ali desenvolvidas estão presentes em "La notion de 'situation' coloniale", primeiro capítulo de seu livro Sociologie actuelle de l'Afrique noire (COPANS, 2001).
} 


\title{
Observando o poder colonial
}

Em Analysis of a social situation in modern Zululand, Gluckman desenvolve a noção de situação social, que consiste em eventos observados pelos antropólogos, através dos quais é possível verificar a validade de suas generalizações (GLUCKMAN, 2010). As situações sociais estão relacionadas com outras situações em um sistema social. Assim, a partir da análise de eventos sucessivos, podemos compreender quais são as configurações que marcam determinada estrutura social. Nesse sentido, o padrão dominante da área pesquisada por Gluckman, isto é, o norte da Zululândia assemelha-se ao de qualquer outra reserva da África do Sul, uma vez que

\begin{abstract}
uma situação social é, em algumas ocasiões, o comportamento de indivíduos como membros de uma comunidade, analisado e comparado com seu comportamento em outras ocasiões. Dessa forma, a análise revela o sistema de relações subjacentes entre a estrutura social da comunidade, as partes da estrutura social, o meio ambiente físico e a vida fisiológica dos membros da comunidade. (GLUCKMAN, 2010: 252)
\end{abstract}

O evento enfatizado por Gluckman é a cerimônia de inauguração da ponte Malungwana - a primeira construída pelo Departamento de Assuntos Nativos. A construção dessa ponte teria dois objetivos: 1) permitir a comunicação do magistrado de Mahlabatini com parte de seu distrito e 2) tornar possível o acesso ao Hospital Ceza, para onde as mulheres zulus acorriam quando necessitavam de atendimento obstétrico.

Gluckman descreve detalhadamente a área onde a ponte foi erguida - inclusive, contamos com o auxílio pictórico de um mapa -, os participantes do evento (europeus, magistrado local, cirurgião do distrito, missionários e funcionários do hospital, comerciantes, policiais etc.), assim como as ações e falas desses atores no decorrer da cerimônia.

Embora os europeus estivessem de um lado e os zulus, de outro, é significativo que "quase todos os altos dignitários zulus trajavam roupas de montaria europeia, embora o rei estivesse usando um terno de passeio. Pessoas comuns trajavam combinações variadas de roupas europeias e zulus" (GLUCKMAN, 2010: 245-246). Apesar de a cerimônia ter sido iniciada com uma canção do clã do chefe local, entoaram, logo em seguida, um hino inglês. Do mesmo modo, o magistrado fez um discurso em inglês, traduzido simultaneamente para o zulu pelo seu funcionário zulu. Seguindo o exemplo dos europeus, os zulus aplaudiram os discurSOS (GLUCKMAN, 2010).

A Zululândia moderna era uma estrutura compartilhada por brancos europeus e zulus, de modo que há uma única comunidade branco-africana cujos grupos possuem modos específicos de comportamento. Os eventos ocorridos na ponte devem ser relacionados a um sistema composto, em parte, pelas relações entre zulus e europeus. Tais relações - marcadas por separação e reserva -, conforme Gluckman (2010: 253), "podem ser estudadas como normas sociais, como pode ser demonstrado pela maneira como zulus e brancos adaptam, sem coerção, seu comportamento uns aos outros".

Gluckman elenca diferentes motivos e interesses que levaram àquelas pessoas à inauguração da ponte. Para os zulus, a inauguração era um evento mais local do que para os europeus: enquanto a maioria destes sabia do evento, a maioria dos zulus de Nongoma sequer sabiam da existência da ponte. Na Zululândia, além do regente, somente o governo pode promover um evento de importância pública para zulus e europeus. Isso porque o poder político tanto do governo quanto do rei zulu constitui forças organizatórias. 


\begin{abstract}
O magistrado planejou a cerimônia, teve o poder para organizá-la dentro dos limites de certas tradições sociais e pôde fazer inovações de acordo com as condições locais. Mas, obviamente, a divisão das pessoas em grupos e muitas das ações não foram planejadas. A configuração subsidiária e não planejada dos eventos do dia tomou forma de acordo com a estrutura da sociedade zululandesa moderna. (GLUCKMAN, 2010: 256)
\end{abstract}

Sob essa perspectiva, assim como o evento tomou forma em conformidade com a estrutura social, esta foi solidificada pela situação social. A separação entre europeus e zulus durante a inauguração ganha significado quando outros padrões de comportamento são observados. "Essa separação”, segundo Gluckman (2010: 257), "envolve mais do que a diferenciação axiomaticamente presente em todas as relações sociais. Pretos e brancos são duas categorias que não devem se misturar (...). Na Zululândia, um africano nunca poderá transformar-se num branco". A manutenção dessa separação - expressa nas políticas de "segregação" e "desenvolvimento paralelo" - é um valor dominante para os brancos.

Balandier (2014: 56) reconheceu a importância de se relacionar os aspectos "modernistas" observados pelos antropólogos à situação colonial, caminho seguido, entre outros, por Fortes e Gluckman que consideram, como ressaltei acima, "que, no caso da África negra colonizada, sociedade negra e sociedade branca participam integralmente de um mesmo conjunto, abordando a noção de 'situação"”.

Em sua tentativa de sistematizar um arcabouço teórico que pudessem contribuir para os estudos referentes às sociedades colonizadas, Balandier (2014) defendeu que os pesquisadores levassem em consideração a situação colonial, isto é, um conjunto complexo constituído por diferentes domínios, como a história, a economia e o político-administrativo. Nesse sentido, a expansão colonial das nações europeias poderia ser encarada a partir de muitas perspectivas.

O historiador estuda a colonização em diferentes períodos e em função da nação colonial, de modo a compreender as mudanças que ocorrem através das relações entre as nações coloniais e os povos colonizados. Ele revela como o sistema colonial se estabeleceu e passou por transformações, bem como os seus diferentes aspectos políticos, jurídicos e administrativos e as ideologias que justificam esse sistema (BALANDIER, 2014). Em relação a esse último aspecto, Balandier (2014: 38) defende que "não há sociologia dos povos colonizados válida se não se presta atenção às ideologias e aos comportamentos mais ou menos estereotipados que elas suscitam".

Muitos historiadores tendem a afirmar que os processos de "pacificação" e "melhoria" dos países colonizados ocorreram por conta dos interesses das nações ocidentais em oposição aos interesses locais. Mas, além de observar a pressão externa exercida sobre as sociedades colonizadas, o historiador atenta, igualmente, para as reações à tal pressão. As análises das sociedades colonizadas não podem negligenciar "suas condições específicas", que não revelem apenas "processos de adaptação e de recusa, as conduções inovadoras nascidas da destruição dos modelos sociais", mas também expressam "pontos de resistência" dessas sociedades (BALANDIER, 2014: 37).

Um outro ponto de vista diz respeito às razões econômicas que servem à propaganda da política de expansão. Essa dimensão econômica pode ser encontrada nos estudos sobre "imperialismo", sobre a exploração de matérias-primas pelas nações coloniais, a exploração em larga escala, o comércio de importação-exportação e a estagnação econômica dos povos colonizados. Outros estudos têm como 
foco os problemas do campesinato, da proletarização e da constituição de burguesias (BALANDIER, 2014).

Conforme Balandier (2014: 40), além das indicações dadas pelo historiador, o pesquisador que tenha a pretensão de compreender as sociedades colonizadas deve estar atento também às manifestações econômicas. Isso porque "não são somente os contatos de uma civilização de um tipo técnico e de uma civilização de um tipo primitivo, atécnico, que explicam as estruturas destas sociedades". Nesse ponto, Balandier (2014) endossa a crítica que Gluckman fez a Malinowski no que diz respeito ao não reconhecimento do caráter conflituoso das relações.

Em contrapartida, Balandier (2014: 43) cita, em uma nota de rodapé, o trabalho de Gluckman realizado no Leste da África ${ }^{9}$ - juntamente com os de outros "autores de importantes trabalhos" - para criticá-lo pelo fato de ter conduzido suas pesquisas "unicamente em relação à economia e à organização social "primitivas', em função das perturbações trazidas pela economia 'moderna' pelos problemas que estas colocam". Ou seja, apesar das críticas de Gluckman a Malinowski (GLUCKMAN, 1947), para Balandier, parece que o antropólogo sul-africano teria incorrido nos mesmos equívocos ao evocar somente os resultados do "contato". Não obstante, vale ressaltar que Gluckman não deixa de descrever a história da região a partir do uso de fontes historiográficas.

Em outro momento, sem citar Gluckman, Balandier (2014: 42) refere-se às obras de antropólogos anglo-saxões que trabalharam em África, "preocupados, e com razão, com a "practical anthropology". Essas "omissões" de citações, aparentemente propositais, reaparecem em Sociologie actuelle de l'Afrique noire. Atentando para isso, Copans (2011: 39, tradução nossa) opina que "essas ninharias, como o status não-científico, no sentido estrito do termo, de pelo menos metade das referências, confirmam o caráter fundador deste texto: ele não se refere a nenhuma tradição disciplinar, especialmente porque evita a crítica da literatura colonial como tal".

No que diz respeito especificamente à situação criada na África do Sul pelos europeus, Balandier destaca os seguintes fatores:

\begin{abstract}
segregação territorial imposta pelo Native land act, de 1913 (as native areas são constituídas por apenas $12 \%$ da superfície total da União), segregação social legalizada pelo Colour bar act, de 1926, que reduz os trabalhadores negros somente às funções de operários não qualificados, participação medíocre dos negros na renda nacional (representando $69 \%$ da população, eles só retêm $20 \%$ da renda nacional, enquanto os brancos, que formam $21 \%$ da população, compartilham $74 \%$ desta renda), bases raciais e racistas dadas à organização econômica e política, contradições profundas de uma política que organiza a segregação - os brancos temem ser sobrepujados pelos negros -, ao mesmo tempo em que ela deve "mobilizar o máximo de mão de obra indígena", e provocar, em consequência, o êxodo rural causando "proletarização" e "destribalização". (BALANDIER, 2014: 42)
\end{abstract}

Há, ainda, estudos da situação colonial cuja ênfase recai sobre as implicações políticas e administrativas. Nesse caso, há trabalhos que levam em conta o papel desempenhado pelos aparelhos administrativos e judiciários para assegurar a dominação colonial, além de questões relacionadas à degradação rural, ao desenvolvimento do proletariado colonial, à "balcanização mantida ou criada e às rivalidades entre grupos étnicos”. Assim como os aspectos históricos e econômicos, a

9 No texto, não há referência sobre qual seria o trabalho em questão. A citação aparece da seguinte forma: "Citamos, para a África do Sul (I. Schapera, M. Hunter), para a África do Leste (L. P. Mair, Audrey Richards, M. Read, M. Gluckman), para a África do Oeste (M. Fortes, D. Forde, K. L. Little) como autores de importantes trabalhos" (BALANDIER, 2014: 43). De todo modo, vale frisar que Balandier não menciona - pelos menos explicitamente - as pesquisas de Gluckman realizadas na Zululândia. 
dimensão político-administrativa, segundo Balandier (2014), não deve ser esquecida.

De acordo com Balandier (2014), a situação da África do Sul é paradigmática, uma vez que demonstra como as dimensões econômicas, políticas e raciais estão interligadas. Dessa forma, a situação colonial deve ser considerada como um "complexo", uma "totalidade".

\section{Dividir para conquistar}

As observações de Gluckman voltavam-se à vida cotidiana; sobretudo para as tensões entre indivíduos e grupos. Como ressalta Kuper (1978: 170), ele e Leach, a despeito das divergências, "foram atraídos para os problemas do conflito de normas e manipulação de regras, e ambos usaram uma perspectiva histórica ${ }^{10} \mathrm{e}$ o método de caso ampliado para investigar esses problemas". ${ }^{11}$

$\mathrm{Na}$ Zululândia, Gluckman observou que as relações entre europeus e zulus são marcadas por hostilidade e conflito. Entretanto, a cisão entre esses grupos é justamente o fator de sua integração em apenas uma comunidade. Ainda que essa constatação esteja em conformidade com a noção de oposição segmentária desenvolvida pela teoria oxfordiana, Gluckman introduziu em seus trabalhos novas formas de oposição e conflito (KUPER, 1978).

Em "Rituals of rebellion in South-East Africa"12, Gluckman descreveu algumas cerimônias dos Bantos do Sudeste, na Zululândia, Suazilândia e Moçambique, a fim de demonstrar como esses eventos revelavam tensões sociais, motivo pelo qual ele os chamou de rituais de rebelião. Ao contrário do que possa parecer a priori, esses rituais, que seguiam esquemas tradicionais estabelecidos, não questionavam a estrutura social, mas, sim, as distribuições de poder (GLUCKMAN, 2011).

Os Suzi realizavam cerimônias nacionais cujo simbolismo explicitava as tensões que permeavam a vida nacional, assim como o faziam os seus vizinhos Zulu. $\mathrm{Na}$ interpretação de Gluckman (2011: 21), esses rituais não eram “apenas uma declaração maciça de união, mas também uma ênfase no conflito, uma afirmativa de rebelião e rivalidade contra o rei, com afirmações periódicas de união com o rei e de retirada de poder do rei". E mais: "a estrutura política é santificada na pessoa do rei, por ser essa estrutura a fonte de prosperidade e força que protege a nação interna e externamente”.

Gluckman (2011: 23) conclui que, na vida política africana, "os homens eram rebeldes, jamais revolucionários", tendo em vista que a ordem social estabelecida não era questionada. Os atores (o rei, os príncipes reais e os súditos) não apenas aceitavam a ordem existente e suas instituições como realmente acreditavam nelas. "Aqueles que disputavam o poder contra uma autoridade estabelecida queriam apenas conseguir a posição da autoridade para si próprios” (GLUCKMAN, 2011: 23).

O caráter aparentemente paradoxal do conceito de conflito desenvolvido por Gluckman encontra correspondência em sua análise sobre os significados da categoria dívida em diferentes sociedades. Em um dos capítulos de The ideas in

\footnotetext{
10 Para Gluckman, contudo, Leach incorreu em erro ao não colocar a categoria Kachin $h k a$ (disputa entre facções; dívida) em uma perspectiva histórica e comparativa (GLUCKMAN, 1973). Para uma apresentação mais pormenorizada do debate entre esses autores, ver Kuper (1978).

${ }^{11}$ Outra (infeliz) coincidência: tanto Leach quanto Gluckman perderam suas notas de campo durante a guerra (KUPER, 1978).

${ }_{12}$ Este trabalho foi apresentado, primeiramente, como The Frazer Lecture, em 1952. Dois anos depois, foi publicado pela Manchester University Press com o mesmo título. Posteriormente, em 1963, passou a constar em Order and rebellion in tribal Africa, livro de sua autoria (GLUCKMAN, 2011).
} 
Barotse jurisprudence, publicado em 1965, Gluckman utiliza-se dos dados de Leach, que descreve como a dívida possui dois aspectos entre os Kachin: por um lado, caso não seja quitada, pode gerar hostilidades entre facções; por outro, pode significar um estado de dependência e amizade (GLUCKMAN, 1973).

Quando Gluckman iniciou seu trabalho de campo em África, a teoria durkheimiana ainda era prestigiada pela antropologia social inglesa. Seguindo essa perspectiva, os antropólogos sustentavam que as sociedades eram sistemas baseados em valores comuns, na integração, no equilíbrio e na continuidade, de modo que a atividade política estaria voltada à manutenção da ordem (COLSON, 1979).

Ainda sob a influência oxfordiana, Gluckman tratava o conflito como um mecanismo de integração a serviço da manutenção das relações políticas. No entanto, diferentemente de Durkheim e de alguns autores que o seguiam, não tratou o conflito como uma espécie de anomia que colocava em risco o sistema social. Ao contrário, parece ter combinado as ideias do sociólogo francês com as de Simmel13 (COLSON, 1979), para quem o conflito é uma forma de sociação, na medida em que está "destinado a resolver dualismos divergentes; é um modo de conseguir algum tipo de unidade, ainda que através da aniquilação de uma das partes conflitantes" (SIMMEL, 1983: 122).

Em seu livro A history of anthropology, Eriksen e Nielsen (2010: 109) afirmam que "o interesse de Gluckman pelo conflito social foi inspirado por seu radicalismo político e, em última análise, por Marx. Mas diferentemente de Marx (e como Evans-Pritchard), ele via o conflito como um processo que por fim levava à integração".

Para Gluckman, todas as relações sociais têm dois aspectos, quais sejam, a divisão e a fusão. No primeiro caso, interesses divergentes tendem a romper a relação; no segundo, tais interesses divergentes são reconciliados por meio de laços comuns em um sistema de coesão social. Divisão e fusão são inerentes à natureza de uma estrutura social (GLUCKMAN, 2010).

Assim, os conflitos entres grupos tendem a ser equilibrados através da cooperação dos membros desses grupos em outros agrupamentos. No caso dos grupos oponentes da Zululândia, a estabilidade do sistema se deve à coesão social de suas relações econômicas e da força do governo (GLUCKMAN, 2010). Os indivíduos utilizam-se, estrategicamente, de diferentes grupos de modo a “(...) escapar das dificuldades encontradas em um desses grupos. Ao fazer isso, pode até agir contra o que considera serem os interesses de um grupo importante, do qual é membro, sem perceber a contradição do seu comportamento" (GLUCKMAN, 2010: 312).

A participação dos indivíduos em grupos está vinculada, portanto, aos inúmeros interesses, valores e motivos que influenciam seu comportamento em situações diferentes, ou seja, indivíduos pertencentes a certos grupos são membros potenciais de outros (GLUCKMAN, 2010). Gluckman argumenta que "os indivíduos podem, assim, assumir vidas coerentes por meio da seleção situacional de uma miscelânea de valores contraditórios, crenças desencontradas, interesses e técnicas variadas".

Em "La situation coloniale: approche théorique", Balandier dialoga diretamente com os dados empíricos de Gluckman - ainda que nem sempre o cite. Isso porque "a África do Sul é um dos casos mais evocados no artigo. A situação do apartheid é como uma espécie de modelo analítico da situação colonial com suas

${ }^{13}$ Contudo, vale ressaltar que, a despeito dos pontos de convergência entre Gluckman e Simmel, aquele afirmou que desconhecia as ideias do sociólogo alemão quando elaborou seus próprios argumentos (KUPER, 1978). 
sociedades branca e negra, sua dominação racial e sua dinâmica religiosa" (COPANS, 2001, tradução nossa).

Na situação colonial, os grupos em contato podem ser divididos a partir da "sociedade colonial" (grupo dominante) e "sociedade colonizada" (grupo subjugado). Teríamos assim: a) a sociedade colonial, com exceção dos estrangeiros da raça branca; b) os "estrangeiros" da raça branca; c) os coloured (categoria inglesa utilizada para designar mestiços e estrangeiros de cor); d) a sociedade colonizada, isto é, os "nativos". Dispostos hierarquicamente, esses grupos são classificados a partir de critérios raciais e de nacionalidade, postulando "a excelência da raça branca, e, mais precisamente, desta fração - que é a nação colonizadora (a supremacia é dada como fundamentada na história e na natureza)" (BALANDIER, 2014: 47).

Entre os grupos dominados, os coloured são os mais desfavorecidos. Isso porque, em função de representações raciais, são rejeitados tanto pela sociedade colonial quanto pela sociedade colonizada. Mediante a imposição de medidas discriminatórias, são isolados social e espacialmente (BALANDIER, 2014). Em uma nota de pé de página, Gluckman (2010: 266) ressalta que "o termo 'raça' é usado num sentido totalmente não científico na África do Sul. Há muitos escritos e pronunciamentos pseudocientíficos sobre raça”.

Apesar de a sociedade colonizada ser numericamente superior, não deixa de ser uma minoria sociológica. Citando Maunier, Balandier (2014: 50) nos lembra que a "colonização é um fato de poder": o predomínio da tutela em detrimento da autonomia. A dominação colonial "se exprime por um estado de fato (práticas não codificadas, mas que conduzem a uma viva reprovação se não respeitadas) e por um estado de direito". Tal dominação é assegurada por diferentes setores da sociedade colonial responsáveis por domínios específicos, a exemplo do político, do econômico e do espiritual. Ideologicamente, utiliza-se de um sistema de pseudojustificativas de caráter racial (BALANDIER, 2014).

O princípio "dividir para conquistar" é seguido à risca pelas nações coloniais. Ainda que as sociedades colonizadas sejam historicamente divididas étnica e/ou espiritualmente, é notório o uso que o poderio colonial faz dessas divisões, na medida em que as pratica arbitrariamente. No que diz respeito às divisões religiosas, a colonização fomentou oposições entre o cristianismo e religiões locais. Em relação às divisões sociais, temos a separação entre "urbanos" e "rurais", entre "proletários" e "burgueses", entre gerações (BALANDIER, 2014).

Os "contatos" aos quais os povos colonizados estão submetidos são produzidos em condições particulares, ou seja, em uma situação colonial. Nessas condições, uma minoria estrangeira - que se afirma como racialmente superior - impõe seu domínio sobre uma maioria autóctone materialmente inferior. De um lado, uma civilização mecanizada, economicamente poderosa e de origem cristã; de outro, civilizações não mecanizadas, economicamente "atrasadas" e "não-cristãs". Para que essas relações antagônicas sejam mantidas, em outras palavras, para que a dominação seja endossada, os grupos dominantes recorrem à "força" e a um sistema de pseudojustificativas (BALANDIER, 2014).

Tal como Gluckman, Balandier (2014: 58) percebe que, na história das sociedades colonizadas, os conflitos adquirem diferentes graus de intensidade: ora encontram-se em estado de latência, em um período de equilíbrio ou adaptação; ora os conflitos tornam-se explícitos e afloram os antagonismos, em momentos “vividos pelo 'colono' como uma retomada da discussão da ordem estabelecida, 
pelo 'colonizado', como um ensaio de reconquista da autonomia”. Nesses momentos, as "crises" - importante locus de observação da situação colonial - são reveladas.

\section{Equilíbrio, mudança social e processo}

Eriksen e Nielsen (2010: 98) avaliam que "a mudança social não era uma questão em pauta na Inglaterra nem na França, onde ela só seria introduzida na antropologia nos anos 1960 através do trabalho do africanista Georges Balandier e seus alunos". No entanto, ainda que, de fato, tenha recebido pouca atenção antes da década de 1960, não devemos esquecer das importantes contribuições dadas por Gluckman e Leach à essa questão de forma pioneira.

Na terceira parte de seu ensaio sobre a Zululândia moderna, Gluckman propõe uma distinção entre sistemas repetitivos e sistemas em mudança. O equilíbrio repetitivo ocorre quando o repertório cultural é capaz de solucionar o conflito. Em contrapartida, o equilíbrio é colocado em xeque quando a estrutura e o aparato cultural são incapazes de resolvê-lo e a cooperação não pode ser alcançada. Nesse caso, novos conflitos são engendrados à medida em que o conflito central permanece sem resolução. Eis o contexto no qual as mudanças podem ocorrer (GLUCKMAN, 2010).

Para Leach (2014), entretanto, o "equilíbrio" ao qual Gluckman e outros antropólogos britânicos se referem é uma "ilusão". Isso porque, no caso dos Kachins, o "equilíbrio estável” está restrito ao plano das ideias; o mundo empírico, ao contrário, não está ordenado de um modo sistemático, havendo uma oscilação política de longa duração. Kuper (1978: 175-176), igualmente, não vê com bons olhos a oposição proposta por Gluckman entre sistemas repetitivos e variáveis, pois "isso levou-o por vezes a extremos absurdos, que o obrigaram mais tarde a rever a sua posição".

De fato, Gluckman reviu suas posições, quando da publicação de Order and rebellion in tribal Africa, em 1963. Embora Leach (2014: 52) o considerasse o seu "mais vigoroso oponente em matérias teóricas e que defendeu com coerência o tipo de teoria do equilíbrio orgânico", Gluckman aprovou a tese de Leach e reconheceu os equívocos de sua teoria dos sistemas em equilíbrio.

Em 1959, Gluckman apontou, no Congresso Internacional de Stresa14, os inconvenientes do "método da ilustração adequada" (apt illustration method) para os estudos que pretendem dar conta de processos mais amplos da vida social. De maneira autocrítica, observou que, ainda que seus trabalhos entre os Zulu e os Barotse tenham contribuído para o desenvolvimento da antropologia social, seus objetivos acabaram por se concentrar na apresentação das morfologias sociais.

\footnotetext{
Agora me parece claro que, apesar da minha análise [sobre as tomadas de decisão dos juízes Barotse] ter-se desenvolvido através de muitos casos, alguns minuciosamente relatados, estes tinham sido tratados como incidentes isolados trazidos ao tribunal. E, no entanto, é óbvio que cada caso era apenas um incidente num longo processo de relações sociais, com suas raízes mergulhadas no passado, que os seus protagonistas voltariam muitas vezes a viver juntos, e que a interação entre eles seria afetada pela decisão do tribunal. (GLUCKMAN, 1975: 70)
} 
A partir desse momento, ele passou a defender um novo tipo de análise que tratasse os casos como estágios de um processo ${ }^{15}$ dinâmico de relações sociais, mediante o uso do "método de casos desdobrados" (extended-case method). $\mathrm{O}$ antropólogo deve, portanto, descrever e analisar uma série de incidentes ligados às mesmas pessoas ou grupos sociais,

no decorrer de um período suficientemente longo, e demonstrar como esses incidentes, esses casos, se relacionam com o desenvolvimento e a mudança das relações sociais entre essas pessoas e grupos, agindo no quadro de sua cultura e de seu sistema social. (GLUCKMAN, 1975: 68)

Desde 1949, Gluckman estivera alocado na Escola de Manchester, conhecida, dentre outros méritos, pelos estudos que tratavam de questões ligadas ao colonialismo. Os antropólogos dessa instituição argumentavam que a mudança não podia ser reduzida a "um simples objeto de estudo", uma vez que não seria possível compreendê-la descrevendo simplesmente o "antes" e o "depois" da estrutura social (ERIKSEN e NIELSEN, 2010). Ao contrário, "Gluckman e seus colegas mostraram que, quando os efeitos locais de processos globais são investigados empiricamente, eles se dissolvem em redes complexas de relações sociais que estão em constante mudança e influenciam umas às outras" (ERIKSEN e NIELSEN, 2010: 108) ${ }^{16}$.

Já Balandier (2014: 57) sugere que as transformações pelas quais passam as sociedades subjugadas pela colonização podem ser observadas e analisadas a partir das crises que mencionei nos parágrafos acima. Estas não correspondem às fases de um processo supostamente evolutivo; têm, isto sim, "caráteres específicos em função do tipo de sociedade colonizada e da natureza da situação colonial”.

\section{Algumas considerações finais}

A meu ver, quando contrastamos as observações de Gluckman e Balandier, especialmente em relação à África do Sul, percebemos algumas importantes nuances. A análise de Gluckman parece dar maior complexidade àquele contexto etnográfico, principalmente pelo uso das noções de escolha situacional e de conflito.

O quadro oferecido por Balandier, diferentemente, adquire feições mais rígidas em função da utilização frequente das categorias dominantes e dominados ainda que descreva os diferentes grupos que compõem aquela sociedade e que proponha que a análise seja realizada através de várias perspectivas. Por um lado, isso se deve ao caráter de "denúncia" que o texto assumiu e à própria posição política de Balandier17; por outro, se deve ao fato de Balandier não tratar de uma situação colonial específica. Seu texto parece ter a qualidade de propor uma espécie de tipo ideal (a "situação colonial”), que deve ser investigado etnograficamente em diferentes contextos.

A monografia de Gluckman, sem perder de vista as relações assimétricas, dispõe indivíduos, grupos e instituições em um jogo de tabuleiro, ou, para ser mais condizente com a Escola de Manchester, em uma rede complexa de relações so-

\footnotetext{
${ }_{15}$ Aluno de Gluckman, Turner desenvolveu o conceito de drama social enquanto "unidades de processo anarmônico ou desarmônico que surgem em situações de conflito" (TURNER, 2008: 33). Para Turner, os dramas sociais possuem quatro fases de ação pública observáveis: a) ruptura; b) crise; c) ação corretiva; e d) reintegração.

16 "Essa é a ideia por trás da 'teoria de rede' de Barnes, um conceito mais dinâmico do que o de 'estrutura social' de Radcliffe-Brown" (ERIKSEN e NIELSEN, 2010, p. 108).

17 Disponível em: https://www.lemonde.fr/disparitions/article/2016/10/o5/la-mort-de-georges-balandier-sociologuespecialiste-de-l-afrique_5008603_3382.html. Acesso em: 20 dez. 2018.
} 
ciais. Nesse caso, os europeus detêm a posição de dominantes, mas não necessariamente detêm o poder. É o que demonstra Crapanzano (1986) em sua etnografia sobre os brancos da África do Sul. A fim de estudar os efeitos da dominação sobre os dominantes, o antropólogo estadunidense percebeu que estes estão presos ao interior do sistema de dominação da mesma forma que os dominados: ambos possuem uma pequena margem de manobra.

Essa perspectiva pode ser complementada pela noção de campo político de Bourdieu (2015), definido como um espaço onde ocorre uma luta de forças entre polos opostos. Nesse campo, a luta política configura-se como uma "guerra sublimada" (BOURDIEU, 2015) ou como uma guerra continuada por outros meios (SOUZA LIMA, 1995; FOUCAULT, 2018). Isso porque os atores, grupos e instituições lutam pelo poder simbólico de fazer ver e fazer crer, de predizer e de prescrever, de dar a conhecer e de fazer reconhecer, que é ao mesmo tempo uma luta pelo poder sobre os 'poderes políticos' (as administrações do Estado)" (BOURDIEU, 2015: 179).

Lembremo-nos da cerimônia de inauguração da ponte: os discursos proferidos em inglês e zulu, as canções dos Zulu e o hino dos britânicos, a separação entre os participantes do evento, as vestimentas europeias e "nativas" (GLUCKMAN, 2010). Além disso, recordemo-nos da categoria utilizada pelos ingleses para classificar mestiços e estrangeiros de cor (coloured), bem como de todas as legislações que consolidaram o apartheid (BALANDIER, 2014).

A meu ver, o poder que está em jogo nos contextos coloniais não deve ser compreendido como algo unívoco, universal ou supra-histórico. Ao contrário, o poder é relacional e histórico, motivo pelo qual devemos observar o poder em exercício (FOUCAULT, 1995; 2018). É a partir e através das relações de poder que as ações dos indivíduos são afetadas, o que implica na produção de sujeitos e assujeitamentos (FOUCAULT, 1995; 2018).

Sob essa perspectiva, o exercício do poder colonial, em alguns contextos, pode ser compreendido como um poder tutelar (SOUZA LIMA, 1995), uma vez que, enquanto um modo de integração territorial e política, é exercido sobre as ações de determinados grupos e sobre seus territórios. No Brasil, esse poder é exercido, por exemplo, sobre povos e territórios indígenas (SOUZA LIMA, 1995) e sobre populações e espaços urbanos periféricos, como as favelas cariocas (PACHECO DE OLIVEIRA, 2014).

Ademais, o poder tutelar é também um modo de relacionamento e governamentalização de poderes. Em caso de disputas, ele pode mediar sem tomar partido, arbitrá-las de modo a contribuir para a manutenção do conflito ou produzir intencionalmente o dissenso através do já mencionado princípio romano: divide e impera (SOUZA LIMA, 1995).

O conflito aparece, portanto "como forma estruturante fundamental da interação (SOUZA LIMA, 1995: 40), em conformidade com Gluckman (2010; 2011) e Simmel (1983), enquanto o colonialismo (ou a colonização) surge como um "fato de poder" (BALANDIER, 2014) que limita a autonomia de indivíduos e grupos e as condições de possibilidade de se subverter a ordem vigente. 


\section{Referências}

ASAD, Talal. Introdução à Anthropology and the colonial encounter. Ilha - Revista de Antropologia, 19 (2): 313-327, 2017.

BALANDIER, Georges. Antropologia política. São Paulo: Difusão Européia do Livro; Editora da Universidade de São Paulo: 1969.

BALANDIER, Georges. A situação colonial: abordagem teórica. Cadernos CERU, 25 (1): 33-58, 2014.

BOURDIEU, Pierre. "A representação política. Elementos para uma teoria do campo político”. In: O poder simbólico. Lisboa: Edições 70, 2015.

COLSON, Elizabeth. "Antropología política”. In: LLOBERA, José R. (org.). Antropología política. Barcelona: Editorial Anagrama, 1979.

COPANS, Jean. La situation coloniale de Georges Balandier - notion conjuncturelle ou modèle sociologique et historique? Cahiers internationaux de sociologie, 110: 31-52, 2001.

CRAPANZANO, Vincent. Waiting: the whites of South Africa. New York: Random House, 1986

ERIKSEN, Thomas Hylland; NIELSEN, Finn Sivert. História da antropologia. 4. ed. Petrópolis: Vozes, 2010.

FOUCAULT, Michel. "O sujeito e o poder”. In: DREYFUS, Hubert L.; RABINOW, Paul. Michel Foucault, uma trajetória filosófica: para além do estruturalismo e da hermenêutica. Rio de Janeiro: Forense Universitária, 1995.

FOUCAULT, Michel. Em defesa da sociedade. 2. ed. São Paulo: Editora WMF, Martins Fontes, 2018.

GENTILI, Anna Maria. "Antropologia política”. In: BOBBIO, Norberto et al. (orgs.). Dicionário de Política, v. 1. 5. ed. Brasília: Editora Universidade de Brasília; São Paulo: Imprensa Oficial do Estado, 2000.

GLUCKMAN, Max. Malinowski's 'functional' analysis of social change. Africa: Journal of the International African Institute, 17 (2): 103-121, 1947.

GLUCKMAN, Max. "Obrigação e dívida". In: DAVIS, Shelton H. (org.). Antropologia do direito: estudo comparativo de categorias de dívida e contrato. Rio de Janeiro: Zahar, 1973.

GLUCKMAN, Max. "O material etnográfico na antropologia social inglesa". In: GUIMARÃES, Alba Zaluar (Org.). Desvendando máscaras sociais. Rio de Janeiro: Livraria Francisco Alves, 1975.

GLUCKMAN, Max. "Análise de uma situação social na Zululândia moderna". In: FELDMAN-BIANCO, Bela (org.). Antropologia das sociedades contemporâneas: métodos. 2. ed. São Paulo: Editora UNESP, 2010.

GLUCKMAN, Max. Rituais de rebelião no sudeste da África. Série Tradução, v. 1. Brasília: DAN/UnB, 2011. 
KANT DE LIMA, Roberto. "Por uma antropologia do direito, no Brasil". In: Ensaios de antropologia e de direito. Rio de Janeiro: Lúmen Júris Editora, 2008.

KUPER, Adam. Antropólogos e antropologia. Rio de Janeiro: F. Alves, 1978.

LEACH, Edmund Ronald. Sistemas políticos da alta Birmânia. São Paulo: Editora da Universidade de São Paulo, 2014.

NADER, Laura. "Up the anthropologist: perspectives gained from 'studying up'". In: HYMES, D. Reinventing anthropology. New York: Random House, 1972.

PACHECO DE OLIVEIRA, João. “Antropologia política”. In: SILVA, Benedicto (coord.). Dicionário de ciências sociais. Rio de Janeiro: Editora da Fundação Getúlio Vargas, 1986.

PACHECO DE OLIVEIRA, João. Pacificação e tutela militar na gestão e populações e territórios. Mana, 20 (1): 125-161, 2014.

SIMMEL, Georg. "A natureza sociológica do conflito”. In: MORAES FILHO, Evaristo de (org.). Simmel: sociologia. São Paulo: Ática, 1983.

SOUZA LIMA, Antonio Carlos. Um grande cerco de paz: poder tutelar, indianidade e formação do Estado no Brasil. Petrópolis: Vozes, 1995.

TURNER, Victor W. Dramas, campos e metáforas: ação simbólica na sociedade humana. Niterói: EDUFF, 2008. 